addresses his book to all workers in the field of mental and physical defect and one of the opening paragraphs illustrates the merits and demerits of his whole book. ' This book,' he writes, ' attempts to supply the need for an up-to-date reference book for the intelligent lay reader, and particularly, for the professional worker in the fields of special education, handicapped children, mental defect, clinical and abnormal psychology, child guidance, mental hygiene, social service, psychology and paediatrics. It could also serve for the area covered by advanced students in psychology, education and medicine and more particularly, in special education, clinical psychology, mental defects, orthopaedics and neuropsychiatry.'

The 'intelligent lay reader,' however, and most of the intermediate categories of workers that are addressed by Professor Wallin will find that they are assailed by figures and percentages, by opinions and facts, by theories, hypotheses and fancies in bewildering array, all expressed in sentences modelled on the lines of the one quoted.

It is a pity that Professor Wallin has not been able to martial his material into more readable form, for without a doubt, as a reference book for trained doctors, he presents a mass of information and statistics as well as many pages of valuable discussion on important and controversial aspects of mental deficiency. Moreover, when he expresses his own experiences and beliefs, they are reasoned and well balanced. The chapters on the dull and backward child, on the relationship between mental deficiency and mental disease, and much of the matter dealing with the various ways in which mental deficiency can be classified repay careful reading.

The book has a few illustrations of the more spectacular examples of conditions dealt with in the text and, for a book so full of figures and statistics, has surprisingly few tables and charts. Each chapter and many sub-sections are supplied with useful references to the literature and there is a 23-page index. The binding, and particularly the print and paper, are excellent.

\section{A GUIDE TO MEDICINE}

By Ivo Geikie-CobB, M.D. Pp. 4I6. London: George G. Harrap \& Co., Ltd. I950. 15 s.

This book usefully bridges a gap between the professional medical dictionary and the less technical synopsis. Its utility has been deliberately extended to meet the requirements of a wide range of readers, including even that section of the laity which has occasional need for interpreting the language of medicine. Dr. Geikie-Cobb has eniisted the aid of an impressive band of 21 coadjutors, each a distinguished authority in a particular field, who have contributed articles on their respective specialties; these articles are additional to the general text. The arrangement of the book is strictly alphabetical, but an index has been added for the benefit of readers who may be uncertain where to find the information they seek. ThE text is sufficiently up to date to include allusion t $\bar{Q}$ cortisone; in general details of treatment are wisel avoided, having regard to certain classes of readeo into whose hands the book will probably fall. Theauthor and his associates have set themselves the difficult task of compiling a work of reference usefusf alike to doctors, medical auxiliaries, and sucte interested laymen as journalists, barristers, an $\bar{\Phi}$ others whose occupations have points of contact? with medicine, not to speak of those who; nog directly concerned with medical topics, nevertheless wish to have an intelligent appreciation of what? they read and hear. In these times, when the national press and the B.B C. so assiduously address themselves to the medical education of the comst munity, there is certainly a need for a book of this kind.

\section{TUBERCULOSIS NURSING}

By Jessie G. Eyre, S.R.N., T.A. (Hons.). Pp. xi +291 , with 103 illustrations. London: H. K Lewis. I949. 2 Is.

In this book Miss Eyre displays considerable knowledge of the fundamental facts about tubercu= losis and its management and nursing, and she tells in a simple and straightforward manner the story o. the evolution of the disease in the human subjects and the methods of treatment applied. The tgxt covers not only pulmonary disease but the complie cations of phthisis and extra-pulmonary manifeş⿰氵tions. These two are bound rather too closetp together to satisfy the pathological purist, but as the approach is essentially practical this is of little consequence. Of particular value are the sections and appendices devoted to nursing procedurese This book, which is extensively illustrated, will be a help to a nurse engaged in tuberculosis work.

\section{OPHTHALMIC OPERATIONS}

By Seymour Philps, F.R.C.S. Pp. $x+397$, wit 5 Io illustrations. London: Bailliere, Tindall and Cox. 1950. 50s.

Surgical techniques are of necessity the product of personal experience and the value of textbooks is clearly greatest when they provide advice base $\phi$ on the author's tried methods, rather than $\vec{\alpha}$ symposium of current practice. In no fiele perhaps, is this more so than in ophthalmic surgery? and this volume is an excellent work of the firsf type.

The subject is covered in 20 chapters of bol type, and the brief of the title-page has beeto broadly interpreted to include the surgical manage ment of the case as well as the layout of theatre and operating tray. The section devoted to the surgery of retinal detachment, for example, will be valued especially for its blunt insistence upon the overriding importance of pre-and post-operativg management. 